\title{
A língua não-padrão em traduções literárias brasileiras: nova tendência ou legado histórico?
}

\author{
Vanessa Lopes Lourenço Hanes*
}

\section{Resumo}

Há no Brasil uma tendência a elevar o registro do discurso direto em traduções literárias ao introduzir nestes textos elementos linguísticos da norma culta pouco comuns na oralidade. Entretanto, análises de traduções recentes do inglês para o português brasileiro, particularmente daquelas publicadas pósanos 2000, demonstraram tentativas de tradução de variações linguísticas do discurso direto como alguma forma de (pseudo) variação linguística do português brasileiro. Nesse contexto questiona-se: as tentativas de utilização de variação no textoalvo ao traduzir a variação do texto-fonte são realmente fenômeno recente na tradução literária? Ou seria possível encontrar elementos que apontam para uma resistência contra o uso homogeneizado da norma culta ao traduzir o discurso direto não-padrão já nas primeiras décadas do século $\mathrm{XX}$ ? Achados indicam que a tentativa de dar voz às representações do discurso não-padrão em traduções literárias brasileiras utilizando português não-padrão é uma prática relativamente antiga, ainda que nunca tenha sido homogênea.

Palavras-chave: Inglês não-padrão. Variação linguística. Português brasileiro. Literatura traduzida. Estudos descritivos da tradução.

* Doutora em Estudos da Tradução pela Universidade Federal de Santa Catarina (UFSC). Professora Adjunta de Língua Inglesa da Universidade Federal Fluminense (UFF), Niterói, RJ. ORCID: http://orcid.org/0000-0002-0413-0190. 


\title{
Non-standard language in Brazilian literary translations: new trend or historical legacy?
}

\begin{abstract}
There is a historical tendency to elevate the register of direct discourse in translated literature in Brazil by introducing in these texts normative linguistic elements uncommon in Brazilian oral expression. However, analyses of some recent literary translations from English into Brazilian Portuguese, particularly of those published after 2000, indicate that attempts are being made to translate English variations using some (pseudo) variation of Brazilian Portuguese. Given the current context, a major question arises: is using variation in the target language to translate variation in the source language really a recent phenomenon? That is, how far back into the 20th century can resistance to homogenizing normative language be identified in the translation of direct non-standard English discourse? The findings of this study indicate that Brazilian attempts to voice non-standard English with non-standard Portuguese is a relatively old translation practice, although it has never been a homogenous one.
\end{abstract}

Keywords: Non-standard English. Language variation. Brazilian Portuguese. Translated literature. Descriptive translation studies.

Recebido em: 28/02/2020

Aceito em:25/05/2020 
No contexto atual, em que se enfrenta uma volta ao ultraconservadorismo no Brasil em suas diversas facetas, surgem dúvidas a respeito do futuro das políticas tradutórias recentemente adotadas (ou seria mais correto chamá-las de toleradas? Ou ainda conquistadas?) no que tange a tradução para o português brasileiro do discurso literário originalmente escrito visando representar diferentes variações linguísticas, variações estas que muitas vezes também trazem consigo uma intrínseca carga de representatividade de minorias sociais. Essas dúvidas vêm à tona porque achados anteriores já demonstraram que, enquanto por um lado, historicamente há no Brasil uma tendência a elevar o registro do discurso direto em obras literárias traduzidas através da introdução de elementos linguísticos da norma culta (ver Hanes, 2015), por outro análises de traduções literárias recentes do inglês para o português brasileiro, particularmente daquelas publicadas durante os anos 2000, demonstraram que há tentativas de tradução de variações linguísticas presentes no discurso direto de personagens no texto-fonte como alguma forma de (pseudo) variação linguística do português brasileiro. Um exemplo dessa mudança recente de abordagem tradutória seria a obra Adventures of Huckleberry Finn, de Mark Twain: somente na tradução brasileira de 2011, feita por Rosaura Eichenberg, os personagens falantes de dialeto foram, pela primeira vez, representados através de recursos linguísticos indicativos de linguagem não-padrão em português, após um longo percurso de retraduções desta mesma obra utilizando o português segundo a norma culta. Esta abordagem foi possível, em grande parte, pela aparente flexibilidade da Editora L\&PM, que se propôs - ou ao menos não se opôs - a comercializar no país traduções literárias que fizessem uso de uma gramática brasileira não-padrão. Segue 
abaixo um trecho de diálogo entre os personagens Huck e Jim na tradução de Eichenberg para demonstrar os recursos utilizados por ela na representação da língua não-padrão:

- Ocê tem braços e peito peludo, Jim?

- Pra quê fazê essa pergunta? Num tá veno que tenho?

- Bem, ocê é rico?

- Não, já fui rico uma veiz e vô sê rico de novo. Uma veiz eu tinha catorze dólar, mas comecei a ispeculá e perdi tudo. (TWAIN, 2011. p. 58) ${ }^{1}$

Embora o futuro das políticas tradutórias acerca da variação linguística representada em obras literárias seja o ponto que levou às primeiras reflexões que originaram este estudo, a realidade é que ele não se trata de uma tentativa de prever objetivamente o futuro do comportamento tradutório normativo no sentido preconizado por Toury (1995), que entende as normas tradutórias como um construto social consensual. Trata-se, pelo contrário, de uma volta ao passado para buscar pistas que colaborem com o entendimento da representação das variedades linguísticas nãopadrão anglófonas em traduções literárias brasileiras. Propõese assim um olhar ao passado que teria relevância para melhor entendimento do presente e projeção do futuro.

Este artigo se insere, portanto, na intersecção entre as áreas da sociolinguística e dos Estudos da Tradução, lançando mão também de conhecimentos de outras áreas do saber para buscar respostas, ainda que parciais, ao grande questionamento: será

\footnotetext{
1 "Have you got hairy arms and a hairy breast, Jim?"

"What's de use to ax dat question? Don' you see I has?"

"Well,, are you rich?"

"No, but I ben rich wunst, and gwyne be rich again. Wunst I had foteen dollars, but I tuck to specalat'n', en got busted out." (TWAIN, 1958. p. 40)
} 
que as tentativas de utilização de variação no texto-alvo na tradução da variação presente no texto-fonte são realmente um fenômeno recente no universo da tradução literária das últimas décadas? Ou seria possível encontrar elementos que apontam para uma resistência ao uso homogeneizado da norma culta ao traduzir o discurso direto representativo de dialetos já nas primeiras décadas do século XX? Embora não seja possível chegar a respostas definitivas neste artigo, acredita-se que este questionamento pode ser abordado parcialmente através de alguns estudos de caso.

A hipótese inicial que motivou a pesquisa aqui descrita foi a de que as representações do discurso anglófono nãopadrão traduzido utilizando o português brasileiro não-padrão se confirmariam como um fenômeno relativamente recente, atrelado a diversos acontecimentos históricos - com especial destaque ao período pós-ditadura militar, que teria resultado em maior abertura às pluralidades sob diferentes perspectivas, inclusive a linguística. Tal hipótese foi adotada com base no conhecimento de que esta é a realidade no tocante aos escritos vernáculos, como coloca Moreira:

A língua padrão foi, pelo menos até o início do século $\mathrm{XX}$, a base da literatura ocidental em geral e brasileira em particular. Mesmo que o escritor tivesse a licença poética para inventar sons, palavras, sintaxes e sentidos novos, ou seja, para se desviar das normas cultas da língua, não era comum a aproximação de uma variedade falada menos prestigiada da língua. (MOREIRA, 2008, p. 01)

Assumiu-se, portanto, que a abordagem tradutória, que segundo Toury (1995) tende a ser conservadora e se espelhar no que é aceito como literatura pela cultura receptora, desenvolver- 
se-ia nos mesmos moldes nas primeiras décadas do século XX. E esta perspectiva se fortaleceu graças a achados prévios especificamente atrelado à tradução; afinal, como afirma Paganine (2011, p. 282) em sua pesquisa de doutoramento acerca dos escritos de Thomas Hardy, "(h)istoricamente, o sistema brasileiro de literatura traduzida tendia a não traduzir a variante dialetal", e, por outro lado, "isso vem mudando aos poucos e os tradutores têm se sentido mais à vontade para arriscar na tradução de variantes não-padrão" (PAGANINE, 2011, p. 282). Todavia, não pareceu correto equacionar tendências com a onipresença de um fenômeno linguístico e tradutório sem uma consulta, ainda que breve, de produtos literários traduzidos naquele momento histórico.

Falar em discurso "não-padrão" pode erroneamente levar a entender que se parte da perspectiva de que há, em algum lugar, um "padrão" a ser atingido. Lippi-Green (2007), referindo-se ao contexto anglófono norte-americano, afirma que a língua padrão é nada mais do que um mito. Assim sendo, é de fundamental importância estabelecer que a utilização da combinação de termos "representações não-padrão" busca descrever aquelas ocorrências de discurso direto em que o inglês utilizado pelas personagens literárias diverge do que é preconizado enquanto norma culta em inglês e em português, ainda que pensando este entendimento de não-padronização sob uma perspectiva crítica e concordando com a ideia de que por trás do não-padrão há uma outra norma (o)culta (BAGNO, 2003, p. 52).

Compreende-se, portanto, que a empreitada aqui delineada lida com conceitos amplamente debatidos (e nem sempre consensualmente definidos) pela comunidade acadêmica nacional e internacional. $\mathrm{O}$ próprio entendimento de língua não-padrão 
e o que pode ser entendido como suas ramificações, a saber, os conceitos de dialetos, variações e variedades linguísticas, exemplificam muito bem a complexidade da temática. Gadini e Woitovicz (2007) afirmam, talvez exageradamente, que a principal discussão da linguística tem se dado ao redor da distinção entre língua e dialeto. Independentemente de sua primazia como ponto de debate na linguística, os conceitos de dialeto, de variantes e de variação linguística são realmente explanados de maneiras diversas por diferentes autores. Consideramos que Halliday (1985) explana didaticamente o que seriam o registro (um conceito que também é de grande importância para este estudo) e o dialeto. Para ele, há dois tipos de variação na língua: as variações sociais e as variações funcionais. Os dialetos seriam as variações linguísticas ligadas a um grupo social específico, de uma região geográfica específica e com seu próprio sistema léxico, sintático e fonético. O registro, por sua vez, refere-se às variações relacionadas às funções para as quais a língua é utilizada, ou seja, a adequação da língua a diferentes contextos. Com relação ao termo variedades linguísticas, é compreendido como as diferentes formas de manifestação da fala em uma língua, as quais incluem dialetos, socioletos e idioletos (ver Lippi-Green, 2007). Estas definições servem para direcionar o debate proposto, e não se ambiciona colocá-las como apropriadas a qualquer contexto de pesquisa.

Embora no presente estudo não se vise fazer uma análise meticulosa acerca de qual dialeto, variação ou variedade específico é representado no corpus trabalhado, vale mencionar que é preciso ter cautela para não incorrer no erro relativamente comum no Brasil de referir-se a determinadas ocorrências de língua não-padrão como uma unidade linguística coesa, de 
maneira sobremodo simplista. Um exemplo concreto: Bailey (2007) esclarece que os afro-americanos utilizam um amplo espectro de variedades linguísticas atreladas a determinadas regiões geográficas específicas, e não têm um modo único de falar, embora haja sim elementos compartilhados entre diferentes variedades; entretanto, é relativamente comum encontrar referências ao inglês afro-americano em pesquisas acadêmicas sem maior consideração das diversas nuances englobadas por esta denominação.

Uma vez que este artigo é desenvolvido ao redor de ocorrências de discurso direto em obras literárias, um conceito que necessita ser problematizado é o de representações da oralidade na literatura. Como bem coloca Azevedo (2003), há um consenso na academia de que a principal manifestação da língua é o discurso oral, uma vez que, com a exceção das línguas de sinais, todas as línguas se desenvolveram inicialmente no âmbito da oralidade. Só muito mais tarde, como explana Ong (2002), originou-se a língua escrita. E, apesar de todos os esforços empreendidos, esta língua escrita, seja ela qual for, não consegue, em sua totalidade, representar a língua oral. Partese aqui, portanto, do entendimento de que há limitações nestas representações, uma vez que existem características da oralidade que não são passíveis de representação no discurso escrito, obras literárias inclusas. Halliday (1985) indica que as características prosódicas e paralinguísticas da língua falada, por exemplo, não são objeto de fácil representação na forma escrita. Britto (2012) também explana que elementos da fala tais como sentenças incompletas, redundâncias e outros geralmente não podem ser representados por escrito, o que afasta os textos escritos da oralidade real. Diante dessas limitações, as representações da 
oralidade analisadas serão entendidas com o auxílio do conceito de "oralidade fingida", um termo cunhado por Goetsch (1985) ao se referir à mimese da língua oral em formato ficcional.

Há ainda que se considerar as diferenças entre o contexto situacional em que se inserem as ocorrências do inglês nãopadrão e aquelas do português brasileiro não-padrão. Retomando mais uma vez a questão do inglês afro-americano como exemplo, Bagno (2014) esclarece que, enquanto nos Estados Unidos a segregação racial levou ao surgimento de uma língua especificamente negra, no Brasil não se tem um português falado exclusivamente pelos negros, mas sim uma língua dos segmentos sociais mais pobres que, em grande parte, são compostos por negros. E essa diferenciação, é claro, afeta diretamente a dinâmica tradutória de textos orais e escritos que envolvam o inglês afro-americano para o português brasileiro. Britto (2012) chega a afirmar que, neste contexto, as perdas ao traduzir são inevitáveis. Alva e Salgueiro (2010) também abordam e se dizem frustrados com o que percebem como uma perda de perspectiva literária na tradução de Their eyes were watching God de Zora Neale Hurston para o português brasileiro, a qual equaciona o inglês afro-americano com uma variedade do português das classes menos favorecidas mencionado acima. Não se objetiva aqui emitir juízos de valor acerca da propriedade ou nãopropriedade de estratégias tradutórias como aquela abordada por Alva e Salgueiro (2010), mas sim demonstrar com este exemplo o desafio que a tradução do discurso não-padrão representa para o profissional de tradução.

O primeiro texto a ser considerado como corpus, o qual despertou inicialmente o questionamento norteador do presente estudo e já parcialmente o respondeu, foi uma tradução brasileira 
de A Certain Dr. Thorndyke, realizada por L. Cunha e intitulada O Incrível Dr. Thorndyke, a qual foi publicada em 1933 pela Livraria do Globo. Este romance policial britânico de autoria de R. Austin Freeman foi originalmente publicado em 1928 e se inicia no Golfo do Benim, contando, portanto, com personagens africanos. Essa obra foi parte da primeira grande leva de traduções de obras literárias anglófonas de massa no Brasil, e surpreendentemente apresentava traços de discurso não-padrão, conforme é perceptível nas ocorrências abaixo, ambas traduções do discurso direto de um personagem negro (cuja versão original pode ser consultada nas notas de rodapé deste artigo):

- "Mastah - disse êle, com calor, - Para a casa é melhor. Este lugar nada bom. A gente é muito "braba"". (FREEMAN, 1933, p. 10). ${ }^{2}$

- “Sim, $m i$ sabe.” (FREEMAN, 1933, p. 10). ${ }^{3}$

Foi curioso, entretanto, observar que personagens brancos também utilizam o inglês com alguns traços não-padrão nesta obra em seu formato original (ainda que sejam elementos bem menos frequentes e óbvios do que no discurso dos personagens negros); todavia, somente o personagem negro africano é representado como usuário de uma língua portuguesa nãopadrão. Seguem alguns casos em que língua não-padrão e/ ou registro informal foram observados no texto originário no discurso direto de personagens brancos, mas são imperceptíveis na tradução:

- Meus agradecimentos, caro companheiro, - disse êle, após ter desembuchado.

\footnotetext{
2 "Mastah," said he, earnestly, "you go for house one time. Dis place no good. Dem people be angry too much"(FREEMAN, 2011, p.-[Kindle edition])

3 Yass; me sabby. (FREEMAN, 2011, p.-[Kindle edition])
} 
- A moral acima de tudo. Devemos sustentar a dignidade do branco. (FREEMAN, 1933, p. 10). ${ }^{4}$

E, novamente:

- Assim não! - protestou este último. - Tão depressa, não, ouviu? - Os meus chinelos caíram. Deixe-me apanhar os chinelos. (FREEMAN, 1933, p. 10). ${ }^{5}$

Representações da oralidade foram suprimidas, verbos foram acrescentados, e de modo geral o registro do personagem branco foi elevado. Por outro lado, a língua portuguesa nãopadrão vista no discurso brasileiro do personagem negro é claramente associada às classes menos privilegiadas e mais subalternizadas no Brasil, conforme o que já foi mencionado anteriormente. Esta subalternidade é inclusive mantida e explicitada com a manutenção do termo original Mastah, cuja primeira ocorrência vem acompanhada de uma nota de rodapé onde se lê: "Corruptela de master (senhor)" (p.10). Esta utilização do termo original também demonstra a presença de outra abordagem tradutória considerada mais predominante em tempos atuais; a estrangeirização, conforme denominação cunhada por Venuti (1995). Mas, voltando à utilização da representação não-padrão da língua portuguesa, mesmo nos breves trechos selecionados é possível notá-la na omissão de verbos, na utilização pronominal e conjugação verbal incorretas, e na seleção de vocabulário. Ademais, esse uso não-padrão é salientado por diferentes recursos gráficos: aspas e itálico.

Esse primeiro achado quase que acidental (de uma abordagem tradutória inesperada em uma obra literária sendo

\footnotetext{
4 "Many thanks, dear chappie," said he, when he had removed the obstruction; "moral s'pport most valuable; uphold dignity of white man" (FREEMAN, 2011, p.- [Kindle edition])

5 "Here, I say!" protested the latter, "nosso fast, d'ye hear? I've dropped my slipper. Lemme pick up my slipper." (FREEMAN, 2011, p.-[Kindle edition])
} 
pesquisada com outro intuito investigativo) provocou curiosidade acerca da hipótese inicial já sedimentada na concepção da autora deste estudo: aquela de que a utilização do português não-padrão na tradução de obras anglófonas no Brasil seria um fenômeno recente, posterior aos anos 2000.

Diante disso, o próximo passo metodológico para responder a este recém-surgido questionamento foi buscar adquirir ou acessar traduções brasileiras antigas de obras anglófonas nas quais o discurso não-padrão fosse significativo para o próprio entendimento do sentido da obra em questão, tornando-se aparentemente central na sua abordagem tradutória. Supôs-se que, se o caso observado em O Incrível Dr. Thorndyke fosse se repetir, essa repetição provavelmente se daria em obras desta natureza.

Encontrar literatura de décadas anteriores no Brasil para a realização de estudos acadêmicos é um grande desafio, em especial no que tange obras mais antigas, uma vez que as bibliotecas nacionais são bastante deficitárias, e por conta do fato de que a preservação de acervos bibliográficos de maneira que sejam conservados a longo prazo parece ser uma preocupação relativamente recente. Vale ainda acrescentar a estes fatores o interesse relativamente baixo no passado em trazer ao público brasileiro obras anglófonas permeadas pela língua não-padrão, as quais podiam ser vistas como obscuras e secundárias em importância ou prioridade em um momento histórico em que mesmo os livros tidos como cânone no cenário internacional ainda careciam de tradução.

Levando estes fatores em conta, pesquisas online foram realizadas acerca da possibilidade de duas obras literárias haverem sido traduzidas no Brasil em um passado relativamente 
distante, devido à sua grande relevância no contexto de origem: Gone with the wind, de Margaret Mitchell, lançada em 1936, e Uncle Tom's cabin, obra de Harriet Beecher Stowe originalmente publicada em 1852. Acreditava-se que esses livros poderiam ter sido selecionados para tradução devido à sua relevância histórica, sendo que o primeiro se trata de uma das mais detalhadas narrativas ficcionais a respeito do sul dos Estados Unidos no contexto da guerra civil norte-americana, aclamada por público e crítica; e o segundo, afirma-se, foi considerado pelo próprio presidente norte-americano Abraham Lincoln um dos estopins para que a referida guerra civil ocorresse. Com relação a Gone with the wind, sua adaptação para o cinema em 1939 também foi considerada um possível incentivo para que existisse uma tradução brasileira mais antiga daquela obra, já que a tradução de obras literárias somente após o sucesso de suas adaptações fílmicas parece ser uma das tônicas que têm há décadas movido o mercado literário nacional. Esta linha de raciocínio se provou correta: ambas as obras haviam sido traduzidas no Brasil décadas atrás, e restaria agora tentar ter acesso a elas. Por fim, os textos foram obtidos através da loja online de livros novos e usados Estante Virtual, que reúne catálogos de diversas lojas físicas em todo o país. Para localizá-los, uma busca foi realizada pelas traduções de acordo com os títulos brasileiros encontrados nas pesquisas prévias via Google: E o vento levou e A Cabana do Pai Tomás.

A obra de Mitchell foi publicada no Brasil em 1940 pela Irmãos Pongetti Editores, uma editora do Rio de Janeiro sobre a qual pouco pôde ser descoberto. Sabe-se, entretanto, que foi uma das editoras mais conceituadas do Brasil na década de 1940, e era capitaneada pelos irmãos Rodolfo e Ruggero 
Pongetti, o último havendo inclusive atuado como presidente do Sindicato Nacional dos Editores de Livros entre 1960 e 1962. Henrique e Arruda (2013) mencionam que os proprietários da Irmãos Pongetti Editores eram simpáticos e bem-relacionados, tinham um espírito pioneiro, e davam oportunidades a autores ainda novos e poucos conhecidos do público. Esta tradução de E o vento levou foi assinada por Francisca de Basto Cordeiro, que além de tradutora foi também uma autora publicada pela Irmãos Pongetti Editores e alcançou considerável sucesso, o que merece destaque quando se considera a sua condição de mulher no Brasil do início do século XX. Ela foi membro de diversas instituições ligadas às Letras, como o P.E.N. Club no Rio de Janeiro.

O pioneirismo e a ousadia dos Irmãos Pongetti podem ser percebidos claramente em um elemento paratextual pouco usual encontrado nas primeiras páginas da tradução, logo após a folha de rosto, o qual tem ligação direta com a temática central do presente artigo: uma carta escrita à tradutora Francisca de Basto Cordeiro pela autora da obra, Margaret Mitchell, datando de junho de 1939. Esta carta, que aparece em português, provavelmente em tradução da própria Cordeiro uma vez que Mitchell afirma desconhecer absolutamente o português, traz um agradecimento daquela autora pelo árduo trabalho da tradutora em verter um texto que Mitchell considera difícil por suas peculiaridades linguísticas tão arraigadas nos regionalismos do estado norte-americano da Geórgia. Ela afirma nunca ter pensado que seu livro seria traduzido, e coloca que "A natureza dos negros tem sido a pedra em que tropeçam algumas versões estrangeiras, uma vez que não existe população negra em muitos países europeus tornando-se portanto, intraduzível a sua 
maneira de falar" (MITCHEL, 1940, p. 5). Mitchell conclui sua carta de maneira muito cordial dando ao trabalho de tradução de Cordeiro o crédito pelo eventual sucesso da obra no Brasil.

Foi deveras positivo encontrar tal elemento paratextual que tem grande relevância para este estudo, pois traz à tona exatamente a questão da tradução da fala não-padrão anglófona para o português brasileiro, demonstrando que a tradutora não só fez questão de traduzir língua não-padrão como língua nãopadrão do Brasil, mas também de se comunicar com a autora do texto originário explicitando sua opção tradutória, talvez em uma tentativa de obtenção de respaldo para fazer algo inesperado naquele momento histórico.

Alguns exemplos da abordagem tradutória de Carneiro seguem. O primeiro traz a fala de um escravo chamado Jeems:

- Não sinhô, ossuncês não disse nada p'ra ela ficá de mau humô. Parece p'ra mim que ela inté ficô muito contente de vê ocês, parecia inté que viu passarinho verde, mas porem, quando falaro do casamento do Sinhô Ashle com Sinhá Méli Hamiton, ela ficou muda como passarinho quando vê gavião avoá. (MITCHELL, 1940, p. 15). ${ }^{6}$

Eis aqui uma ocorrência do discurso da personagem Mammy, ou Babá, na tradução de Cordeiro. Trata-se da escrava mais importante da família da personagem principal da obra, Scarlett O'Hara:

- Ocê tem tanta inducação como as galinha, e Sinhá Elena e eu teve tanto trabaio à toa! Inda pr'u cima está aí fora cum o sereno da noite caindo, e sem chale! Quanta vez eu falei das febre que dá condo a gente fica nos ar da noite, cos ombro descoberto? Vem p'ra dentro,

6 Nawsuh, Ah din' notice y'all say anything ter mek her mad. Look ter me lak she sho glad ter see you an' sho had missed you, an' she cheep along happy as a bird, tell 'bout de time y'all got ter talkin' 'bout Mist' Ashley an' Miss Melly Hamilton gittin' mah'ied. Den she quiet down lak a bird w'en de hawk fly ober”. (MITCHELL, 2010. p.-_[Kindle edition]) 
Nhã Scarlett! (MITCHELL, 1940, p. 24). ${ }^{7}$

Com relação à obra de Beecher Stowe, a tradução mais antiga encontrada data de 1957, e foi lançada no Brasil pela editora Edições Paulinas, sem indicação do tradutor responsável. Sousa e Amorim (2015) conduziram um estudo sobre o que denominam traduções e adaptações dessa mesma obra de Beecher Stowe, e trazem à luz alguns elementos pertinentes para a análise desenvolvida aqui. O primeiro deles é que consideram esta publicação da Edições Paulinas como uma adaptação, e não uma tradução, um entendimento plenamente justificável diante da omissão de vários trechos da obra original nessa edição. Outra informação obtida através desses autores é que é possível encontrar no site da Edições Paulinas, hoje conhecida como Paulus Editora, que "sua função é evangelizar, mudar a sociedade e guiá-la por um caminho que considera mais humano e cristão, e não há motivos para crer que suas intenções fossem diferentes no momento em que publicou A Cabana do Pai Tomás" (SOUSA; AMORIM, 2015, p. 550-551). Talvez devido ao seu público-alvo, e à função evangelizadora e de certa forma didática assumida pela editora, percebe-se o uso da língua padrão na tradução do discurso direto não-padrão de personagens como Aunt Chloe:

- Os Lincolns, coitados, não sabem o que é uma boa cozinheira - respondeu, desdenhosa, a tia Cloé - São, sem dúvida, pessoas de posição, mas, comparados com os senhores, que diferença! (STOWE, 1957, p.15)

O mesmo trecho segue em seu formato no texto originário:

\footnotetext{
7 'You ain' got no mo' manners dan a fe'el han', an' after Miss Ellen an' me done labored wid you. An' hyah you is widout yo' shawl! An' de night air fixin' ter set in! Ah done tole you an' tole you 'bout gittin' fever frum settin' in de night air wid nuthin' on yo' shoulders. Come on in de house, Miss Scarlett". (MITCHELL, 2010. p.--[Kindle edition])
} 
"Dem Lincolns ain't much count, no way!" said Aunt Chloe, contemptuously; "I mean, set along side our folks. They's 'spectable folks in a kinder plain way; but, as to getting up anything in style, they don't begin to have a notion on 't. (STOWE, 1852 [2017], p.[Kindle edition])

Abaixo é apresentado outro exemplo em que o inglês não-padrão é traduzido como português padrão, no discurso da pequena escrava Topsy:

- Pode me bater o dia inteiro - balbuciou a pequena, que começava a perturbar-se - que eu digo a mesma coisa. Só vi esta fita quando a senhora a descobriu na minha manga. Quem sabe se ela não entrou lá sozinha? (STOWE, 1957, p. 92)

A Topsy brasileira gera estranhamento, por exemplo, ao usar uma colocação verbo-pronominal correta segundo a norma culta (a descobriu) mas, de modo geral, extremamente incomum no discurso oral, mesmo para brasileiros adultos e letrados. O texto em inglês diz:

"Laws, Missis, if you's to whip all day, couldn't say no other way", said Topsy, beginning to blubber. "I never seed dat ar. - it must a got caught in my sleeve". (STOWE, 1852 [2017], p.-[Kindle edition])

Diante dos exemplos extraídos das traduções consideradas, parece oportuno retomar o questionamento inicial: o que essas obras revelam acerca da hipótese inicial deste artigo, a qual previa o apagamento da língua não-padrão em traduções literárias menos recentes? Resumidamente, acredita-se ser possível afirmar que os achados deste estudo indicam que, ao contrário da hipótese inicial, a tentativa de dar voz às representações do discurso não-padrão em traduções literárias brasileiras através 
do uso de português não-padrão é uma prática tradutória relativamente antiga, ainda que nunca tenha sido homogênea, e que não seja possível colocá-la como a prática tradutória mais comum em nenhum momento histórico. Já nas décadas de 1930 e 1940 os exemplos apresentados nas traduções dos textos de Freeman e Mitchell mostram não só a utilização do português não-padrão, mas, no último caso, uma conscientização a respeito da importância deste recurso tradutório na transmissão do conteúdo do texto original. Por outro lado, a apresentação ao público leitor da correspondência entre autora e tradutora aponta para a possível necessidade de justificar a abordagem tradutória pouco usual.

É impossível ignorar ainda que a editora que sobrevive até hoje, coincidentemente ou não, foi aquela que optou por apagar os traços do discurso não-padrão na tradução da obra de Stowe, livrando-se do uso de língua "incorreto" e "indesejado". Esta abordagem é, ainda na atualidade, uma das tônicas da tradução no Brasil, e se fez muito presente durante décadas que se sobrepõem (mais uma vez, coincidentemente ou não) ao período do regime militar brasileiro. Naquele momento, muitas vezes textos traduzidos eram trabalhados segundo um ideal linguístico nacional quase que machadiano (ver Hanes, 2015), o qual era e em certa medida continua a ser equacionado com uma boa tradução, que consequentemente gozará de sucesso mercadológico. Assim, recorrendo à teoria dos polissistemas de Even-Zohar (1990), é cabível afirmar que o conservadorismo linguístico sempre ocupou o centro do polissistema de literatura traduzida no Brasil, com a utilização do português segundo a norma culta para a representação do discurso não-padrão como a norma tradutória predominante. Por outro lado, o breve 
corpus analisado aqui atesta que abordagens periféricas em que o português não-padrão é adotado na representação do discurso anglófono não-padrão traduzido têm coexistido no país com esta predominância da norma padrão já há décadas.

Retomando o caso da tradução e das retraduções de Adventures of Huckleberry Finn, sabe-se que a abordagem da língua não-padrão só foi realmente mudada após os anos 2000, na quarta tradução disponibilizada no país, demonstrando que, portanto, a tendência dominante do uso da língua padrãona tradução conforme mencionada por Paganine (2011) se manteve como verdadeira por muitas décadas naquele caso e, possivelmente, em muitos outros. Mas a relevância dos achados aqui apresentados é poder apontar que já há tempos aquela não é a única abordagem possível, mesmo em editoras prestigiosas como a Irmãos Pongetti foi no passado, mostrando uma possível associação entre abordagens periféricas sendo já há tempos aceitas por editoras respeitadas ou bem-estabelecidas (o que é, de certo modo, também o caso da L\&PM no Brasil de hoje). Interessantemente, elementos dos quais Eichenberg lança mão, em 2011, para caracterizar a fala não-padrão de Jim já haviam sido usados há mais de setenta anos por Cordeiro ao traduzir o texto de Mitchell (um exemplo retirado da amostra apresentada anteriormente comum a ambas as traduções seria a fusão sistemática do $l h$ com a semivogal, em termos como trabaio). Vale ressaltar ainda que, assim como na tradução da obra de Mitchell, de 1940, a tradução contemporânea de Eichenberg também precisou vir acompanhada de uma longa nota da tradutora, antes do início do texto, explanando o porquê da presença da língua não-padrão por todo o livro. o que demonstra a perseverante postura conservadora esperada atualmente do leitorado brasileiro em geral.

Parece relevante mencionar ainda que a relação entre a 
atribuição de subalternidade social e o uso de língua na tradução, conforme indicado nos achados relativos à tradução do texto de Freeman ao abordar diferentemente o falar de personagens brancos e negros, é uma temática abordada indiretamente neste artigo mas relevante para maior investigação futura, em especial no contexto étnico-racial brasileiro e tendo em mente os frutíferos debates recentes acerca de questões afins.

Indo para além da temática diretamente trabalhada, foi surpreendente também observar um alto grau de estrangeirização na tradução da obra de Freeman, elemento que merece maior atenção e estudo sistematizado, uma vez que pode ser lido como demonstração de certo pioneirismo tradutório ou, por outro lado, simplesmente prova da tradução como agente de colonização linguística.

Em suma, os achados demonstram irrefutavelmente que as normas tradutórias secundárias ou mesmo as idiossincrasias tradutórias de que trata Toury (1995) sempre estiveram presentes. Utilizando mais uma vez a terminologia cunhada por EvenZohar (1990), o questionamento da utilização de língua nãopadrão para representar língua não-padrão em discurso direto no polissistema de literatura traduzida brasileiro não teve início após os anos 2000, mas vem se desenvolvendo basicamente desde a gênese da tradução de obras anglófonas no país, como se vê já no começo da década de 1930 no exemplo da Livraria do Globo. Por outro lado, a abordagem que prioriza o uso da língua normativa como no caso de A Cabana do Pai Tomás sempre esteve firme e forte em sua posição de dominância, respondendo à norma social e historicamente construída do que seria uma tradução aceitável.

E o que essas evidências do passado têm a dizer sobre o 
comportamento tradutório de hoje e as perspectivas tradutórias no cenário atual? O maior legado talvez seja demonstrar que as abordagens dissidentes da norma dominante sempre ocorrerão, mesmo em momentos históricos que pareçam menos propícios para a sua existência.

\section{Referências}

ALVA, Rodrigo; SALGUEIRO, Maria Aparecida Andrade. Zora Neale Hurston and Their Eyes Were Watching God: the construction of an African-American female identity and the translation turn in Brazilian Portuguese. Lexington: Lambert Academic Publishing, 2010.

AZEVEDO, Milton. Vozes em branco e preto: a representação literária na fala não-padrão. São Paulo: EDUSP, 2003.

BAGNO, Marcos. A norma oculta: língua \& poder na sociedade brasileira. São Paulo: Parábola Editorial, 2003.

BAGNO, Marcos. Genocídio, migração forçada e contato na formação do português brasileiro. Revista de Humanidades e Letras, v. 1, n. 1, p. 4-15, 2014.

BAILEY, Guy H. African American English. In: JOHNSON, E; MONTGOMERY, M. (Ed.). The New encyclopedia of southern culture. Chapel Hill: The University of North Carolina Press, 2007, v. 5, p. 29-35.

BRITTO, Paulo Henriques. A tradução literária. Rio de Janeiro: Civilização Brasileira, 2012.

EVEN-ZOHAR, Itamar. Polysystem theory. Poetics Today, Durham, v. 11, n. 1, p. 3-26, 1990.

FREEMAN, R. A. A Certain Dr. Thorndyke. Cornwall: House of Stratus, 2011. E-book Kindle. 
FREEMAN, R. A. O Incrível Dr. Thorndyke. Tradução de L. Cunha. Porto Alegre: Livraria do Globo, 1933.

GADINI, S. J.; WOITOVICZ, K. J. Noções básicas de folkcomunicação. Ponta Grossa: Editora UEPG, 2007.

GOETSCH, Paul. Feigned orality in the narrative styles of developed literary cultures ${ }^{+}$oral and literate language in the 19th-century novel. Poetica-zeitschrift fur sprach-und literaturwissenschaft, v. 17, n. 3-4, p. 202-218, 1985.

HALLIDAY, Michael Alexander Kirkwood. Spoken and written language. Hong Kong: Oxford University Press, 1985.

HANES, V. L. L. The language of translation in Brazil: written representations of oral discourse in Agatha Christie. 2015. 308 f. Tese (Doutorado em Estudos da Tradução) - Programa de Pós-Graduação em Estudos da Tradução, Universidade Federal de Santa Catarina, Florianópolis, 2015. Disponível em: < https:// repositorio.ufsc.br/handle/123456789/158404?show=full $>$. Acesso em: 30 maio 2018.

HENRIQUE, Joyce Kelly Barros; ARRUDA, Talita Nascimento. O exílio de Elisa: a produção literária da primogênita Lispector. In: XIII CONGRESSO INTERNACIONAL DA ABRALIC: Internacionalização do Regional. 2013, Campina Grande, PB. Anais... Campina Grande, PB: Editora Realize, 2013. Disponível em: < https://www.editorarealize.com.br/revistas/ abralicinternacional/trabalhos/Completo_Comunicacao_oral_ idinscrito_531_b34b42cdc8a10fad3631ce98c07a2e3f.pdf>. Acesso: 13 set. 2019.

LIPPI-GREEN, R. English with an accent: language, ideology and discrimination in the United States. New York: Routledge, 2007.

MITCHELL, Margaret. Gone with the wind. Adelaide: Ebooks Adelaide, 2010. E-book Kindle.

MITCHELL, Margaret. ... E o vento levou. Tradução de 
Francisca de Basto Cordeiro. Rio de Janeiro: Irmãos Pongetti Editores, 1940.

MOREIRA, W. C. Literatura e variedade caipira: os caipiras de Valdomiro Silveira. In: Linguasagem. V. 4, 2008. Disponível em: $<$ http://www.letras.ufscar.br/linguasagem/edicao04/04_019. php>. Acesso em: 01 nov 2011.

ONG, Walter. Orality and literacy: the technologizing of the world. New York: Routledge, 2002.

PAGANINE, Carolina Geaquinto. Três contos de Thomas Hardy: tradução comentada de cadeias de significantes, hipotipose e dialeto. 2011. 314 f. Tese (Doutorado em Estudos da Tradução) - Programa de Pós-Graduação em Estudos da Tradução, Universidade Federal de Santa Catarina, Florianópolis, 2011. Disponível em: < https://repositorio.ufsc. br/handle/123456789/95499>. Acesso em: 12 set 2019.

SOUSA, Thaís Polegato de; AMORIM, Lauro Maia. As Relações entre tradução e adaptação e as variações da identidade negra em A Cabana do Pai Tomás, de Harriet Beecher Stowe. Trabalhos em Linguística Aplicada, v. 54, n. 3, p. 545-568, 2015.

STOWE, H. Beecher. Uncle Tom's cabin. Seattle: Amazon Classics, 2017. E-book Kindle.

STOWE, H. Beecher. A Cabana do Pai Tomás. São Paulo: Edições Paulinas, 1957.

TWAIN, Mark. Adventures of Huckleberry Finn. Boston: Riverside Editions, 1958.

TWAIN, Mark. As Aventuras de Huckleberry Finn. Tradução de Rosaura Eichenberg. Porto Alegre: L\&PM, 2011.

TOURY, Gideon. Descriptive translation studies and beyond. Amsterdam: John Benjamins, 1995.

VENUTI, Lawrence. The translator's invisibility: a history of translation. New York: Routledge, 1995. 